\title{
PELATIHAN PUBLIC SPEAKING DI KOMUNITAS STAND UP INDO BOGOR PUBLIC SPEAKING TRAINING IN INDO BOGOR STAND UP COMMUNITY
}

\author{
Muhamad Ridwan ${ }^{1}$, Sukarelawati ${ }^{2}$, Maria Fitriah ${ }^{3}$ \\ ${ }^{123}$ Ps. Sains Komunikasi, Fakultas Ilmu Sosial dan Ilmu Politik \\ Universitas Djuanda Bogor \\ *Korespondensi: Muhamad Ridwan, ridwanremin@gmail.com
}

\begin{abstract}
Talent event stand up comedy television in Indonesia to cause the number of people who want to learn this art by joining to communities to study to be a komika by following a variety of training one of them is public speaking training. The purpose of this research to see how process of training public speaking of the community Stand Up Indo Bogor. This research in a qualitative deskiptif by using two technique data collection the primary and secondary data. The results of the study showed the training process public speaking of the community Stand Up Indo Bogor reference of a high effective communication namely by train communicator, prepare the message, control the audience, see the quality of media the messenger, and get an as expected. The conclusion of this research is training public speaking in a community Stands Up Indo Bogor has been running well in accordance with the process of effective communication, but there are additional training materials needed to become a komika as the training techniques non-verbal (expression and gesture), adjusting references, exchanging experiences to analyze the audience, doing sound checks before performing, and making the audience laugh as feedback.
\end{abstract}

Keywords: stand up comedy; public speaking; community; training.

\section{ABSTRAK}

Ajang pencarian bakat stand up comedy di pertelevisian Indonesia menyebabkan banyaknya orang yang ingin mempelajari kesenian ini dengan bergabung ke komunitas untuk belajar menjadi seorang komika dengan mengikuti berbagai pelatihan salah satunya pelatihan public speaking. Tujuan penelitian ini untuk mengetahui bagaimana proses pelatihan public speaking di komunitas Stand Up Indo Bogor. Penelitian ini menggunakan metode deskiptif kualitatif dengan menggunakan dua teknik pengumpulan data yaitu data primer dan data sekunder. Hasil penelitian menunjukan proses pelatihan public speaking di komunitas Stand Up Indo Bogor mengacu pada sifat-sifat komunikasi efektif yaitu dengan melatih komunikator, mempersiapkan isi pesan, menguasai audiens, memperhatikan kualitas media penyampai pesan, dan mendapatkan respon yang sesuai harapan. Kesimpulan penelitian ini adalah pelatihan public speaking di komunitas Stand Up Indo Bogor sudah berjalan baik sesuai dengan proses komunikasi efektif, adapun terdapat penambahan materi pelatihan yang dibutuhkan untuk menjari seorang komika seperti adanya pelatihan teknik non-verbal (mimik dan gestur), penyesuaian referensi, bertukar pengalaman untuk menganalisis audiens, melakukan cek sound sebelum tampil, dan membuat audiens tertawa sebagai umpan balik.

Kata kunci: stand up comedy; public speaking; komunitas; pelatihan.

Ridwan Remin, Sukarelawati, Maria Fitriah 2020. Pelatihan Public Speaking di Komunitas Stand Up Indo Bogor. Jurnal Komunikatio 6 (1): 7-19 


\section{PENDAHULUAN}

Di pertelevisian Indonesia saat ini seni stand up comedy sangat begitu populer. Menurut Pragiwaksono (2012), program stand up comedy awal muncul di televisi tahun 2011 dengan nama program Stand Up Comedy Indonesia (SUCI) yang digelar oleh Kompas TV. Menurut Giovanni (2019), adanya ajang pencarian bakat tersebut banyak menginspirasi orang-orang untuk ikut berkarier sebagai seorang stand up comedian. Hal ini menjadi salah satu faktor bertambahnya talenta-talenta baru di dunia stand up comedy

Menurut Pragiwaksono (2012), stand up comedy adalah sebuah genre di dalam komedi, biasanya satu orang di atas panggung melakukan monolog yang lucu dan memberikan pengamatan, pendapat, pengalaman pribadinya, mengutarakan keresahan, mengangkat kenyataan, memotret kehidupan sosial masyarakat, dan menyuguhkannya dengan jenaka.

Sehubungan dengan itu (Denny, 2019), mengatakan bahwa komunitas Stand Up Indo Bogor adalah komunitas yang menjadi sebuah wadah bagi orangorang yang memiliki minat terhadap dunia stand up comedy sebagai sebuah seni komedi, yang di mana memiliki visi dan misi untuk mencetak komika-komika handal dan berkualitas bukan hanya dapat menghibur, namun dapat juga memberi ilmu atau wawasan baru pada penonton.

Pada penelitian yang dilakukan oleh Suwandana (2019) menemukan bahwa di dalam komunitas biasanya para komika akan melakukan proses belajar dan berdiskusi tentang stand up comedy bersama para pembina atau komika senior di dalam komunitas pada kegiatan pelatihan stand up comedy sebelum melatih dan menampilkan jokes-nya langsung di hadapan penonton pada kegiatan Open mic. Adapun yang dimaksud dengan Open mic adalah sarana untuk siapa pun, baik itu komika yang lucu ataupun tidak, yang veteran atau yang amatir, untuk naik panggung dan menjajal kemampuannya (Pragiwaksono, 2012).

Kegiatan pelatihan tujuannya adalah untuk menciptakan komika profesional yang memiliki tiga poin penting yaitu: memiliki public speaking/penyampaian yang baik; memiliki karakter/personal brand yang kuat; dan dapat melakukan penampilan stand up comedy dengan durasi satu jam (Pragiwaksono, 2012).

Pragiwaksono (2012), dalam stand up comedy yang menjadi faktor penting ialah public speaking. Menurut Hojanto (2018), kemampuan public speaking yang baik akan mendukung dan mempermudah sampainya informasi, pesan, materi dari komunikator kepada komunikan secara lebih efektif dan efisien. Hojanto (2018), mengemukakan bahwa public speaking memiliki lima komponen, yaitu: penyampai pesan; isi pesan; penerima pesan; media penyampai pesan; umpan balik.

Berdasarkan uraian di atas maka dapat diambil rumusan masalah yaitu: Bagaimana pelatihan public speaking di komunitas Stand Up Indo Bogor? 


\section{MATERI DAN METODE}

\section{Materi}

Hojanto (2018), menjelaskan bahwa public speaking memiliki lima komponen yang hampir sama dengan komponen komunikasi yang efektif yaitu: 1. Penyampai Pesan atau Komunikator

Pembicara harus memperhatikan teknik-teknik dasar public speaking yang meliputi teknik vokal dan verbal sehingga dapat menampilkan showmanship.

2. Isi Pesan

Pesan yang harus disampaikan harus singkat, padat, dan mudah dicerna.

3. Penerima Informasi/Komunikan

Pembicara harus cerdas dalam melakukan analisis audiens, minimal analisis psikologis dan demografi.

4. Media Penyampaian Pesan

Mudah tidaknya suatu informasi diterima dan dicerna oleh audiens juga dipengaruhi oleh media yang digunakan. Dalam hal ini, media berperan sebagai sarana pembantu penyampaian informasi. 5. Umpan Balik

Salah satu indikator suksesnya penyampaian informasi adalah adanya respons/feedback dari penerima informasi. Dapatkan feedback dari audiens dengan mengamati bahasa tubuh mereka, apakah mereka mengantuk, bosan, cemas, atau antusias dengan ciriciri mata berbinar, bertepuk tangan, berpartisipasi menjawab pertanyaan, atau aktif memberikan respons.

\section{Metode}

Penelitian ini menggunakan jenis penelitian kualitatif deskriptif yaitu penelitian yang bertujuan untuk membuat deskripsi secara sistematis, faktual, dan akurat tentang fakta-fakta dan sifat-sifat populasi atau objek tertentu (Kriyantono, 2012).
Teknik pengumpulan data pada penelitian ini menggunakan dua teknik pengumpulan data yaitu, data primer dan data sekunder. Data primer adalah sumber data yang langsung memberikan data kepada pengumpul data. Sedangkan data sekunder adalah sumber data yang tidak langsung memberikan data kepada pengumpul data melainkan melalui orang lain atau dokumen (Sugiyono, 2014).

Adapun dalam penelitian ini menggunakan data primer dan data sekunder sebagai berikut:

1. Data Primer

Menurut Martono (2015), data primer sebagai sekumpulan informasi yang diperoleh peneliti langsung dari lokasi penelitian melalui sumber pertama (responden, informan, melalui wawancara) atau melalui hasil pengamatan yang dilakukan.

a. Wawancara

Kartono dalam Gunawan (2013), menjelaskan bahwa wawancara adalah suatu percakapan yang diarahkan pada suatu masalah tertentu, ini merupakan proses tanya jawab lisan, di mana dua orang atau lebih berhadapan secara langsung.

Selanjutnya Kerlinger dalam Gunawan (2013), mengatakan bahwa wawancara adalah situasi peran antarpribadi berhadapan pertanyaan yang dirancang untuk memperoleh jawaban-jawaban yang relevan dengan masalah penelitian kepada seseorang yang diwawancarai atau informan.

b. Obsevarsi

Menurut Kartono dalam Gunawan (2013), observasi ialah studi yang disengaja dan sistematis tentang fenomena sosial dan gejala-gejala psikis dengan jalan pengamatan dan pencatatan.

2. Data Sekunder 
Menurut Iskandar (2009), data sekunder mencakup pada sumbersumber kepustakaan sebagai berikut:

a. Buku teks, Tesis, dan Disertasi.

b. Jurnal penelitian. c. Abstrak dan Indeks.

d. Media Cetak (Majalah, Surat kabar harian).

e. Media elektronik (TV, Radio, Internet)

\section{HASIL DAN PEMBAHASAN}

\section{Hasil Penelitian}

Stand up comedy adalah kesenian yang sangat mengandalkan kemampuan public speaking untuk menghasilkan respon yang diharapkan dari penonton (tertawa). Menurut hasil wawancara dengan Dede Kendor pada tanggal 9 September 2019, pukul 20.30 WIB, "Stand up comedy sendiri masih menggunakan dasar dari ilmu public speaking. Cara menyampaikan pesan yang baik masih menggunakan teknik public speaking yang baik dengan menggunakan gestur yang baik dan pesannya pun harus tersampaikan". Pendapat tersebut juga dikuatkan oleh pernyataan Pandji Pragiwaksono dalam wawancara pada tanggal 7 Oktober 2019, "Gua ngutip dari Jerry Seinfeld ajalah yang kita anggap dewanya stand up comedian lah, udah sukses secara finansial, sukses secara karir, dihormati juga. Dia bilang gini, stand up comedy tuh $2 \%$ nulis, sisanya the why you do it. Artinya dia aja yang kita kagumi penulisannya merasa tulisan tuh cuma $2 \%$ sisanya tuh cara dibawakannya, artinya delivery-nya, artinya kemampuan kita berbicara di depan publik, makanya krusial sekali. Kalo lu mau mengesamping-kan faktor public speaking dan cuma nulis komedinya doang, ya gak jadi stand up comedian, jadi penulis komedi. Dan kesuksesan jokes kita nyampe apa nggak kan kemampuan kita untuk menguraikan dengan benar yang ada di kepala kita ke benaknya penonton. Itu public speaking. Makanya menurut gue krusial sih".
Kedua pernyataan di atas menunju-kan urgensi dari adanya pelatihan public speaking untuk orangorang yang ingin menjadi komika. Hal tersebut juga diyakini oleh Dede Kendor yang mengatakan, "Karena komikakomika yang baru datang tidak memiliki atau tidak mengetahui dasar dari ilmu public speaking, maka sebelum memasuki ke cara bagaimana stand up comedy perlu diajarkan terlebih dahulu mengenai bagaimana public speaking yang baik dan benar".

Adapun syarat untuk memiliki public speaking atau penyampaian pesan yang baik adalah dengan memenuhi komponen-komponen dalam komunikasi yang efektif. Seperti yang dijelaskan Hojanto (2018), public speaking memiliki lima komponen yang hampir sama dengan komponen komunikasi yang efektif yaitu penyampai pesan/komunikator, isi pesan, penerima informasi/komunikan, media penyampaian pesan, dan umpan balik.

a. Penyampai Pesan/Komunikator Menurut teori Hojanto (2018), pembicara harus memperhatikan teknikteknik dasar public speaking yang meliputi teknik vocal dan verbal sehingga dapat menampilkan showmanship.

Sejalan dengan teori di atas, maka untuk menjadi stand up comedian profesional seorang komika perlu melatih teknik vocal dan verbal. Seperti yang disampaikan oleh Jui Purwoto selaku komika senior di komunitas Stand Up Indo Bogor dalam wawancara pada 
tanggal 10 September 2019 pukul 22.00 WIB, "Pertama suara harus jelas terdengar agar tujuan tercapai, karena itu modal utamanya. Artikulasi, intonasi, dan dinamika dijaga biar tidak jenuh".

Adapun bentuk pelatihan yang diterapkan di komunitas Stand Up Undo Bogor menurut Dede Kendor, "Perlu ada materi mengenai dasar dari public speaking seperti cara penyampaian menggunakan bahasa verbal maupun non-verbal. Dan dengan teori mengenai punch line yang sesuai dengan kaidahnya. Perlu ada latihan baca, diskusi dengan orang lain, memberanikan diri untuk buka pembicaraan dengan orang yang tidak dikenal, sampai mereka tertarik dengan obrolan yang dibawakan". Sementara itu Pandji Pragiwaksono menjelaskan cara untuk melatih public speaking, "Jadi salah satu jalan paling biasa adalah sesering mungkin public speaking (berbicara di depan umum), dan itu pun gak mudah. Yang kedua juga gak mudah, ini yang gua yakini kalo pengen pinter public speaking harus banyak baca. Iya, karena salah satu kendala terbesar orang public speaking adalah tidak menemukan kata yang mau dirangkai menuju ujung kalimat".

Sejalan dengan yang disampaikan oleh Pandji Pragiwaksono, bentuk pelatihan di komunitas Stand Up Indo Bogor dilakukan sesuai dengan kebutuhan dari masing-masing komika. Menurut Rifky Mulyadi Gusti selaku cofounder Stand Up Indo Bogor dalam wawancara pada 19 September 2019, pukul 20.00 WIB, "Menyesuaikan dari kemampuan komika itu sendiri. Kalau memang ternyata komika itu masih lemah dari segi pelajaran bahasa Indonesia, maka akan dianjurkan untuk kembali membaca buku pelajaran di masa sekolah agar kemampuannya tentang bahasa mereka bisa menjadi lebih baik".
Melatih kemampuan public speaking memang diperlukan kesabaran dan ketekutan untuk mau mempelajarinya dari hal-hal dasar yang belum dikuasai. Selanjutnya komika juga dilatih untuk memiliki keberanian dalam berbicara. Seperti yang ditambahkan Rifky Mulyadi Gusti, "Komunitas selalu memberi ruang kepada komika baru untuk berbicara saat pelatihan, baik itu bercerita tentang dirinya sendiri, pendapatnya tentang orang lain, atau opininya tentang isu-isu yang sedang terjadi saat ini untuk menambah keberanian dalam menyampaikan pendapatnya. Ketika sudah berani, maka tahapan selanjutnya adalah menilai pendapatnya tersebut apakah sudah sesuai dengan struktur logika berpikir atau belum, karena pendapat yang baik adalah pendapat yang bisa diterima oleh orang lain, dan itu berhubungan dengan logika berpikir orang lain apakah bisa menangkap pendapatnya dengan baik dan benar atau belum".

Dalam pelatihan stand up comedy di komunitas Stand Up Indo Bogor, komika baru tidak hanya mendapatkan pelatihan untuk meningkatkan kemampuan teknik vocal atau verbar, tetapi juga diberikan materi pelatihan non-verbal untuk meningkatkan kualitas public speaking dalam melakukan sebuah pertunjukan. Seperti yang disampaikan oleh Pandji Pragiwaksono, "Intinya adalah dari sisi public speaking apa pun persenjataan yang lu punya untuk memperkuat jokes tersebut sebisa mungkin lu manfaatkan. Kalo gue, 'bingung' tuh gue tunjukin pake wajah gue (mimik). Gerak tangan membantu. Arah badan membantu, kayak misalnya kita lagi mencoba untuk act out dialog dua orang, arah tubuh tuh juga membantu (gestur). Bahkan jeda yang sebenernya tidak ada gerak, tidak ada suara sekalipun 
juga adalah bagian dari public speaking secara keseluruhan".

Setelah komika berhasil menguasai kemampuan non-verbal (mimik dan gestur), selanjutnya dalam pelatihan di komunitas Stand Up Indo Bogor juga diajarkan teknik delivery atau penyampaian. Materi pelatihan itu disampaikan oleh Dany Beler selaku komika senior di komunitas Stand Up Indo Bogor dalam wawancara pada 8 September 2019, pukul 20.00 WIB, "Materinya ada timing (kepekaan terhadap kalimat, penjedaan antara kalimat satu dengan yang lain), dan pace (kecepatan dalam berbicara yang harus dijaga)".

Hal terakhir yang menjadi pelengkap dalam pelatihan untuk menjadi penyampai pesan/komunikator yang baik adalah dengan melakukan latihan pembadanan (menghapalkan materi) sebelum tampil. Bentuk latihannya berbeda setiap komika sesuai dengan kenyamanan masing-masing. Seperti misalnya yang kerap dilakukan oleh Jui Purwoto, "Latihan pembadanan, jalan kaki dan melakukan praktik di tempat umum agar bisa mempersiapkan diri untuk situasi terburuk". Latihan pembadan ini tujuannya untuk lebih mempersiapkan diri sebelum tampil. Jui Purwoto menambahkan, "Bila seorang komika tidak menghapal materinya, komika jadi meraba-raba materi apa yang harus disampaikan, dan hal itu akan membuat penampilan komika tidak maksimal karena tampil penuh kekhawatiran akibat kurangnya persiapan seperti itu bisa mempengaruhi mental".

Menurut hasil wawancara di atas memperkuat teori yang dikemukakan Hojanto (2018) tentang komunikator yang perlu memperhatikan teknik-teknik dasar public speaking yang meliputi teknik vocal dan verbal sehingga dapat menampilkan showmanship. Namun, selain teknik vocal dan verbal, dalam pelatihan public speaking di Komunitas Stand Up Indo Bogor juga diberikan pelatihan non-verbal seperti mimik dan gestur, kemampuan timing, kemampuan pace, dan kemampuan pembadanan materi.

b. Isi Pesan

Menurut Hojanto (2018), pesan yang disampaikan harus singkat, padat, dan mudah dicerna.

Isi pesan dalam stand up comedy adalah materi lawakan atau jokes. Sejalan dengan teori yang dipaparkan Hojanto di atas, dalam pelatihan standup comedy di komunitas Stand Up Indo Bogor komika dilatih untuk bisa membuat jokes yang singkat, padat, dan jelas. Seperti yang disampaikan Rifky Mulyadi Gusti, "Dalam seni yang bicara tentang kreativitas dan ketidakteraturan ada keteraturan di dalamnya, seperti di musik ada not balok, dan tangga nada. Dalam stand up comedy pun ada teori dan keteraturannya. Komika butuh keteraturan untuk mempersiapkan penampilannya di jangka waktu yang panjang di panggungpanggung besar yang punya tekanan, dan ekspektasi tertentu kepada performer. Di komunitas Stand Up Indo Bogor, ada standar urutan menyusun jokes, biasanyanya jokes yang paling lucu ditempatkan di akhir penampilan, dan jokes yang paling lucu kedua ditempatkan di awal, karena biasanya dalam sebuah penampilan, yang akan diingat oleh penonton adalah bagian awal dan akhirnya. Rumusnya 2-5-4-3-1. Itu teknik standar yang perlu dikuasai oleh komika baru dengan kebutuhan durasi penampilan 5 sampai 10 menit".

Urutan penyampaian jokes merupakan hal yang penting untuk diperhatikan oleh komika dalam sebuah 
penampilan. Hal tersebut juga diyakini oleh Dany Beler, "Karena menyusun urutan penyampaian jokes sangat penting, ibarat seperti menyusun sebuah strategi".

Hal lain yang penting dalam isi pesan atau jokes dari seorang komika adalah masalah referensi antara komika dan penonton yang harus disamakan. Seperti yang disampaikan Rifky Mulyadi Gusti, "Komedi itu tidak akan terjadi kalau penonton tidak mengerti atau tidak tahu referensi dari materi yang disampaikan. Skill itu yang harus dipelajari oleh komika untuk bisa membuat penonton mengerti tentang referensi dari materi yang akan disampaikannya". Pernyataan tentang referensi ini dikuatkan oleh Pandji Paragiwaksono yang mengatakan, "Jadi kalo misalkan lu stand up comedian cuma belajar dari stand up sayang menurut gua, lu belajar stand up comedy, belajar dari dunia non stand up (di luar stand up comedy), yaitu perhatiin ketika misalnya ya, penyanyi lagi ngomong sama penontonnya. Atau pidato, lu bisa ngeliat mana yang baik mana yang buruk".

Bentuk pelatihan di komunitas Stand Up Indo Bogor untuk meningkatkan kemampuan tentang referensi ini adalah dengan melatih penggunaan bahasa saat membuat jokes. Karena menurut Rifky Mulyadi, "Bahasa adalah napas dari komika. Tanpa bahasa yang baik, seseorang mungkin bisa lucu, tapi tidak bisa jadi stand up comedian yang baik".

Penggunaan bahasa mencakup pada pemilihan diksi yang digunakan saat membuat jokes. Hal ini dijelaskan oleh Dede Kendor, "Pemilihan diksi dapat memengaruhi rasa. Untuk komedi harus memilih diksi-diksi yang ada lucunya". Namun, diksi-diksi lucu tersebut harus tetap disesuaikan dengan penonton yang dihadapi. Misalnya ketika berhadapan dengan penonton usia muda, tentu diksidiksi anak muda akan mudah dicerna.
Sebaliknya, jika berhadapan dengan penonton usia dewasa, maka diksi-diksi yang lebih sopan dan umum akan lebih mudah dimengerti. Maka untuk dapat mengatasi hal tersebut komika dilatih agar peka terhadap situasi penonton yang dihadapi. Seperti yang dijelaskan oleh Jui Purwoto, "Stand up comedy bisa dikatakan penyampaiannya menggunakan bahasa apa pun yang cocok dengan siapa yang mendengarkannya. Sampaikanlah dengan kaidah bahasa Indonesia yang benar. Namun, tetap disesuaikan dengan feedback yang akan diberikan oleh penonton. Harus memikirkan bahasa apa yang dapat dimengerti oleh penonton. Ketika Open mic, dan di tampil suatu organisasi lainnya walaupun materinya sama, bahasanya harus dibedakan sesuai dengan siapa yang mendengarnya".

Menurut hasil wawancara di atas memperkuat penjelasan Hojanto (2018) tentang pesan yang disampaikan harus singkat, padat, dan mudah dicerna. Namun, dalam stand up comedy ada hal lain yang perlu diperhatikan seorang komika dalam membuat isi pesan atau jokes, yaitu referensi yang harus disesuaikan dengan audiens sebagai penerima pesan.

c. Penerima Informasi/Komunikan Menurut Hojanto (2018), pembicara harus cerdas dalam melakukan analisis audiens, minimal analisis psikologis dan demografi.

Teori yang dipaparkan di atas sudah sesuai dengan tugas seorang komika sebagai komunikator untuk melakukan analisis audiens. Seperti yang disampaikan Rifky Mulyadi Gusti, "Ketika sudah dibayar maka komika punya kewajiban untuk memenuhi ekspektasi sesuai dengan bayaran tersebut. Komika profesional harus sanggup merespon 
ekspektasi dari orang-orang yang mengaspirasi karya komika tersebut".

Adapun bentuk pelatihan di komunitas Stand Up Indo Bogor untuk meningkatkan kemampuan komika dalam menganalisis audiens adalah dengan mengadakan sharing sesama komika. Hal ini kembali disampaikan oleh Rifky Mulyadi Gusti, "Komunitas selalu mendorong komika untuk sharing sesama komika. Misalnya dari komika senior yang sharing pengalamannya kepada komika junior tentang bagaimana pengalaman tampil di tempat-tempat yang berbeda, hal ini bisa menjadi tambahan wawasan untuk komika junior yang belum bisa tampil di tempat tertentu tapi sudah bisa mempunyai gambaran seperti apa persiapan yang perlu dilakukan untuk tampil di tempat-tempat tersebut".

Selain tukar pengalaman sebagai tambahan pengetahuan, komunitas Stand Up Indo Bogor juga memfasilitasi komika untuk menjajal penampilannya di tempattempat yang berbeda dan penonton yang lebih beragam. Seperti yang dipaparkan oleh Rifky Mulyadi Gusti, "Misalnya kita bikin acara Open mic, yang tujuan ke dalamnya untuk menyediakan panggung kepada anggota komunitas untuk melatih diri, sementara tujuan keluarnya untuk mempromosikan stand up comedy di kota Bogor. Open mic adalah wajah komedi di kota tersebut, maka dari itu penting untuk memberikan standar yang baik di setiap pertunjukannya. Lalu ada juga Open Mic BGR Tour, untuk mencakup pasar yang berbeda dan lebih banyak lagi".

Acara Open Mic BGR Tour diadakan oleh komunitas Stand Up Indo Bogor setiap setahun sekali. Dengan adanya acara ini para komika dilatih untuk tampil di hadapan penonton yang berbeda-beda agar terbiasa menganalisis auidens yang akan mereka hadapi. Hal ini juga diyakini oleh Jui Purwoto, "Mencoba berbagai macam panggung atau latihan di tempattempat yang berbeda dengan latar belakang penonton yang berbeda, agar menjadi terbiasa dengan berbagai macam penonton".

Pengalaman tampil di panggung Open mic dengan penonton yang berbedabeda bisa memberikan pengaruh secara langsung kepada perkembangan komika. Seperti yang disampaikan oleh Dede Kendor, "Dari pengalaman Open mic, karena dapat melihat materi mana yang lebih mendapatkan efek bagi penonton. Dan melihat dari latar belakang penonton seperti latar belakang umur, pendidikan, dan jabatan atau gabungan dari semuanya. Dan materinya bisa dilihat dari keterkaitan penonton dengan konten".

Menurut hasil wawancara di atas komunitas Stand Up Indo Bogor telah melalukan pelatihan yang sesuai dengan pernyataan Hojanto (2018) tentang pembicara harus cerdas dalam melakukan analisis audiens, minimal analisis psikologis dan demografi. Sementara di pelatihan stand up comedy di komunitas Stand Up Indo Bogor analisis audiens dilakukan dalam dua tahap, yaitu ketika sharing komika dan tampil di acara Open mic atau Open Mic BGR Tour.

d. Media Penyampaian Pesan

Menurut Hojanto (2018), mudah tidaknya suatu informasi diterima dan dicerna oleh audiens juga dipengaruhi oleh media yang digunakan. Dalam hal ini, media berperan sebagai sarana pembantu penyampaian informasi.

Teori di atas mengungkapkan betapa pentingnya media penyampai pesan sebagai penentu keberhasilan public speaking. Hal tersebut juga diterapkan pada kesenian stand up comedy yang membutuhkan media penyampai pesan dalam pelaksanaannya. 
Seperti yang disampaikan oleh Jui Purwoto, "Untuk teknis lebih ke sound dan monitor". Menjadi hal yang penting bagi seorang komika untuk memperhatikan kedua perangkat yang akan digunakannya sebelum tampil karena kualitas media akan sangat mempengaruhi penampilan dari seorang komika. Kemudian Jui Purwoto menambahkan, "Mengecek sound untuk menyesuaikan suara dari si komika berdasarkan jenis suara".

Tujuan utama dari cek sound sebelum tampil adalah agar setiap komika bisa menyesuaikan kondisi kedua perangkat itu apakah sudah baik atau belum. Bila ternyata kualitasnya dirasa tidak baik, maka komika akan mengkoordinasikannya dengan tim teknis di acara tersebut sehingga bisa disesuaikan. Atau bila setelah diupayakan ternyata kualitasnya masih kurang baik, maka setiap komika dapat meminta saran kepada komika senior untuk bisa memaksimalkan kondisi kedua perangkat yang ada.

Menurut hasil wawancara di atas maka pelatihan di komunitas Stand Up Indo Bogor sudah sejalan dengan apa yang diterangkan Hojanto (2018) tentang mudah tidaknya suatu informasi diterima dan dicerna oleh audiens juga dipengaruhi oleh media yang digunakan. Dalam hal ini, media berperan sebagai sarana pembantu penyampaian informasi. Maka untuk mengatasi hal itu dalam pelatihan di komunitas Stand Up Indo Bogor komika dilatih untuk melakukan cek sound sebelum tampil.

e. Umpan Balik

Menurut Hojanto (2018), salah satu indikator suksesnya penyampaian informasi adalah adanya respons atau feedback dari penerima informasi. Dapatkan feedback dari audiens dengan mengamati bahasa tubuh mereka, apakah mereka mengantuk, bosan, cemas, atau antusias dengan ciri-ciri mata berbinar, bertepuk tangan, berpartisipasi menjawab pertanyaan, atau aktif memberikan respons.

Dalam konteks stand up comedy respon dari audiens yaitu berupa tawa. Menurut Jui Purwoto, "Mengerti adalah tujuannya, kalau punch line adalah saat penonton tertawa, maka level selanjutnya adalah menggerakkan mereka. Jadi ketika mereka mengerti, kita twist ada punch line mereka tertawa, mungkin yang ketiga adalah pesan. Ketika pesan kita sampai, misal kita menyampaikan masalah tentang buang sampah sembarangan maka penonton akan tergerak untuk melakukannya. Lalu akan memberikan efek kebiasaan (perubahan perilaku) untuk seterusnya".

Dalam pelatihan di komunitas Stand Up Indo Bogor komika baru dilatih untuk bisa membuat isi pesan yang mampu menghasilkan tawa dari penonton. Bentuk pelatihannya adalah dengan mengadakan Gathering komunitas satu kali dalam seminggu. Di saat Gathering, komika baru bisa mencoba jokes yang sudah mereka buat dan mendiskusikannya dengan komika senior. Kemudian komika senior akan memberi masukan terkait jokes yang dibawakan oleh komika baru. Proses ini biasa disebut dengan comedy buddy (combud). Seperti yang disampaikan oleh Warno salah satu komika baru yang aktif melakukan pelatihan yang berhasil diwawancarai pada 24 September 2019, pukul 22.30 WIB, "Prosesnya biasa terjadi pada saat gathering, yaitu komika baru dilatih membawakan materi yang lalu akan dibedah materinya oleh komika senior".

Di komunitas Stand Up Indo Bogor setiap komika yang ingin combud diwajibkan untuk menulis jokes-nya dalam format tabel berisi kolom set up 
dan punch line, kemudian di-print agar bisa dibaca oleh komika senior dan bisa dikoreksi lebih detail.

\section{Contoh Penulisan Materi Stand Up Comedy}

\begin{tabular}{|l|l|}
\hline SET UP & $\begin{array}{l}\text { PUNCH } \\
\text { LINE }\end{array}$ \\
\hline $\begin{array}{l}\text { Saya adalah mahasiswa } \\
\text { yang sangat sibuk, } \\
\text { karena saya kuliah } \\
\text { sambil... }\end{array}$ & Ngekost. \\
\hline $\begin{array}{l}\text { Anak kost itu sibuk, lho. } \\
\text { Kami sibuk... }\end{array}$ & $\begin{array}{l}\text { Bertahan } \\
\text { hidup! }\end{array}$ \\
\hline
\end{tabular}

Dari tabel di atas maka setiap bagian yang ada di punch line adalah saat di mana penonton tertawa, itu adalah tujuan dari umpan balik yang diharapkan dalam stand up comedy.

Menurut hasil wawancara dan observasi di lapangan tersebut maka pelatihan di komunitas Stand Up Indo Bogor sudah sesuai dengan maksud dari Hojanto (2018) tentang salah satu indikator suksesnya penyampaian informasi adalah adanya respons atau feedback dari penerima informasi. Dapatkan feedback dari audiens dengan mengamati bahasa tubuh mereka, apakah mereka mengantuk, bosan, cemas, atau antusias dengan ciri-ciri mata berbinar, bertepuk tangan, berpartisipasi menjawab pertanyaan, atau aktif memberikan respons. Namun, umpan balik yang terpenting dari stand up comedy adalah tawa dari penonton, kemudian level selanjutnya adalah ada efek perubahan perilaku dari penonton setelah menyaksikan sebuah penampilan stand up comedy yang menyampaikan pesan-pesan tertentu.

\section{Pembahasan}

Pelatihan public speaking di komunitas Stand Up Indo Bogor sejalan dengan teori yang dijelaskan oleh Hojanto (2018), public speaking memiliki lima komponen yang hampir sama dengan komponen komunikasi yang efektif yaitu penyampai pesan/komunikator, isi pesan, penerima informasi/komunikan, media penyampaian pesan, dan umpan balik.

Adapun terdapaat beberapa perbedaan untuk menyesuaikan dengan kebutuhan komika seperti halnya pada bagian penyampai pesan/komunikator, Hojanto (2018) hanya menjelaskan seorang pembicara harus memperhatikan teknik-teknik dasar public speaking yang meliputi teknik vocal dan verbal sehingga dapat menampilkan showmanship. Sementara dalam pelatihan public speaking di komunitas Stand Up Indo Bogor juga diberikan pelatihan nonverbal seperti mimik dan gestur, kemampuan timing, kemampuan pace, dan kemampuan pembadanan materi.

Menguasai kemampuan nonverbal seperti mimik dan gestur terbukti dapat meningkatkan kualitas public speaking seorang komika. Sesuai dengan teori yang disampaikan oleh Wahyudi (2013), terdapat tiga faktor pendukung public speaking:

a. Verbal (7\%)

Verbal yaitu bagaimana seorang pembicara memilih kata-kata yang tepat sesuai dengan konsep atau esensi, maksud dan tujuan berbicara di depan umum

b. Vokal (38\%)

Vokal yaitu bagaimana seorang pembicara harus sadar bahwa dia mengeluarkan suara sesuai dengan komoditas pesannya yang akan disampaikan.

c. Visual (55\%) 
Visual yaitu bagaimana seorang pembicara mampu menghadirkan mimik, gestur, dan body language.

Berdasarkan teori di atas maka kemampuan non-verbal (visual) sangat besar pengaruhnya pada public speaking terbukti dari besarnya nilai visual dibandingkan dengan factor pendukung lainnya seperti verbal dan vocal.

(2018) menjelaskan pesan yang disampaikan harus singkat, padat, dan mudah dicerna. Oleh karena itu setiap komika di komunitas Stand Up Indo Bogor dilatih untuk bisa membuat jokes yang efektif dan efisien. Namun, dalam pelatihan di komunitas Stand Up Indo Bogor para komika juga dilatih untuk bisa menyesuaikan referensi dengan audiens, lalu memilih penggunaan bahasa yang tepat, dan menusun urutan penyampaian jokes dengan benar.

Pelatihan untuk menyesuaikan referensi terhadap audiens ini dapat meningkatkan kualitas public speaking seperti dalam teori yang dijelaskan oleh Wrenc (2012), public speaking adalah proses dari perancangan dan pengiriman sebuah pesan kepada audiens. Public speaking yang efektif adalah melibatkan diri dengan pemahaman audiens dan tujuan pembicaraan, memilih topik dasar yang sesuai dengan latar belakang audiens serta mampu mengirimkan pesan dengan terampil.

Berdasarkan teori di atas maka kemampuan menyesuaikan referensi terhadap audiens dapat membuat proses public speaking menjadi lebih efektif.

Pada bagian penerima informasi/ komunikan, Hojanto (2018) menjelaskan pembicara harus cerdas dalam melakukan analisis audiens, minimal analisis psikologis dan demografi. Untuk bisa memiliki kemampuan menganalisis audiens tersebut komunitas Stand $U p$
Indo Bogor melakukan pelatihan dengan cara mendorong komika untuk melakukan sharing pengalaman sesama komika, dan rutin mengadakan acara Open Mic BGR Tour untuk melatih komika menghadapi penonton yang berbedabeda.

Bentuk pelatihan ini diperkuat dengan teori yang dijelaskan oleh Sirait (2008), public speaking merupakan seni yang menggabungkan semua ilmu dan kemampuan yang dimiliki, dan memberanikan diri berbicara di depan umum artinya siap menyampaikan pesan kepada orang-orang yang latar belakangnya berbeda.

Pada bagian media penyampai pesan, Hojanto (2018) menjelaskan mudah tidaknya suatu informasi diterima dan dicerna oleh audiens juga dipengaruhi oleh media yang digunakan. Teori ini sudah sesuai dengan bentuk pelatihan yang ada di komunitas Stand Up Indo Bogor dengan memberikan pelatihan kepada komika untuk melakukan cek sound dan menilai kualitas suara dari monitor sebelum acara OpenMicBGR dimulai agar meminimalisir gangguan secara teknis.

Pada bagian umpan balik, Hojanto (2018) menjelaskan salah satu indikator suksesnya penyampaian informasi adalah adanya respons/feedback dari penerima informasi. Namun, dalam pelatihan public speaking di komunitas Stand Up Indo Bogor bentuk respon yang diharapkan dari audiens menjadi lebih spesifik yaitu berupa tawa, kemudian level selanjutnya adalah ada efek perubahan perilaku dari penonton setelah menyaksikan sebuah penampilan stand up comedy yang menyampaikan pesan-pesan tertentu.

Pelatihan dengan target umpan balik berupa tawa dan perubahan perilaku ini sejalan dengan teori yang dijelaskan oleh Sirait (2008), pembicara 
harus bisa menyampaikan informasi, menghibur, dan meyakinkan pendengarnya. Tanpa kemampuan mengingat cerita lucu dalam urutan yang betul, maka pembicara tidak akan bisa menghibur pendengar.
Teori di atas memperkuat upaya komunitas untuk melakukan pelatihan untuk menghapal jokes sebelum tampil, menyusun urutas jokes dengan benar, dan menyampaikannya dengan baik agar audiens terhibur dan tertawa.

\section{KESIMPULAN DAN IMPLIKASI}

\section{Kesimpulan}

Pelatihan Public speaking di komunitas Stand Up Indo Bogor mengacu pada lima komponen yang hampir sama dengan komponen komunikasi yang efektif yaitu penyampai pesan atau komunikator, isi pesan, penerima informasi atau komunikan, media penyampaian pesan, dan umpan balik. Pada bagian komunikator perlu pelatihan kemampuan non-verbal seperti mimik dan gestur. Karena kemampuan visual ini sangat besar pengaruhnya pada public speaking terbukti dari besarnya nilai visual (55\%) dibandingkan dengan faktor pendukung lainnya seperti vocal (38\%) dan verbal (7\%). Lalu pada bagian isi pesan dibutuhkan pelatihan untuk menyesuaikan referensi dengan audiens sebagai pemerima pesan. Kemudian pada bagian media penyampaian pesan, komunitas Stand Up Indo Bogor yang membiasakan komika untuk melakukan cek sound dan menilai kualitas suara dari monitor sebelum acara OpenMicBGR dimulai agar meminimalisir gangguan secara teknis. Terakhir pada bagian komika baru dilatih oleh komika senior dalam Gathering untuk dapat menghasilkan umpan balik atau respon yang diharapkan dari audiens yaitu berupa tawa dan perubahan perilakunya.

\section{Impilkasi}

Penerapan sifat-sifat komunikasi efektif yang dikemukakan oleh Hojanto (2018) dalam acuan untuk melatih kemampuan public speaking sangat berpengaruh dan fungsional sekali bagi seorang komika yang ingin belajar menjadi profesional.

\section{Implikasi Praktis}

Hasil penelitian ini dapat digunakan sebagai masukan bagi komunitas Stand Up Indo Bogor untuk memperbaiki proses pelatihan public speaking dengan memperhatikan kekurangan dan kelebihan yang terdapat dalam pelatihan sebelumnya untuk semakin meningkatkan kemampuan stand up comedy komika-komika baru di komunitas.

\section{DAFTAR PUSTAKA}

\section{Buku}

Gunawan, I. .2013. Metode Penelitian Kualitatif. Jakarta: PT Bumi Aksara.

Hojanto, O. 2018. Public Speaking Mastery. Jakarta: PT Gramedia Pustaka Utama.
Iskandar. 2009. Metode Penelitian Kualitatif (Aplikasi untuk Penelitian Pendidikan, Hukum, Ekonomi, \& Manajemen, Sosial, Humaniora, Politik, Agama, dan Filsafat). Jakarta: PT Gaung Persada. 
Kriyantono, R. 2014. Teknis Praktis Riset Komunikasi: Disertasi Contoh Praktis Riset Media, Public Relations, Advertising, Komunikasi Organisasi, Komunikasi Pemasaran. Jakarta: Prenada Media Group.

Martono, N. 2015. Metode Penelitian Kuantitatif Teori dan Aplikasi. Jakarta: Rajawali Pers.

Pragiwaksono, P. 2012. Merdeka Dalam Bercanda. Yogyakarta: Bentang Pustaka.

Sirait, Bonar Charles. 2008. The Power of Public Speaking: Kiat Sukses Berbicara di Depan Publik. Jakarta: Gramedia Pustaka Utama. PDF ebook.

Sugiyono. 2014. Metode Penelitian Kuantitatif, Kualitatif dan $R \& D$. Bandung: ALFABETA.

Wrenc, Jason S. 2012. Public Speaking Practice and Ethics. New York: Unnamed Publisher.

\section{Skripsi}

Suwandana D.P\&Ramadhan. 2019. Cara Komunikasi Pembina Komunitas Stand Up Comedy Bogor dalam Membangun Mental dan Teknik Delivery Komika Baru pada Kegiatan Sharing Komika. [Skripsi]. Jakarta (ID). Institut Ilmu Sosial dan Ilmu Politik Jakarta.

\section{Laman}

Denny. 2019. Review Komunitas StandUp \#3: Visi, Misi, Gizi. Diunduh melalui https://standupindobogor.wordpr ess.com/ pada tanggal 2 Juli 2019, pukul 20.00 WIB.

Giovanni. 2019. Banyak Talenta Baru di Stand up, Ernest Prakasa Justru Khawatir. https://kumparan.com/@kumpar anhits/banyak-talenta-baru-distand-up-comedy-ernest-prakasajustru-khawatir1552618148723007355 diakses pada 03 Juli 2019, pukul 22.06 WIB. 